
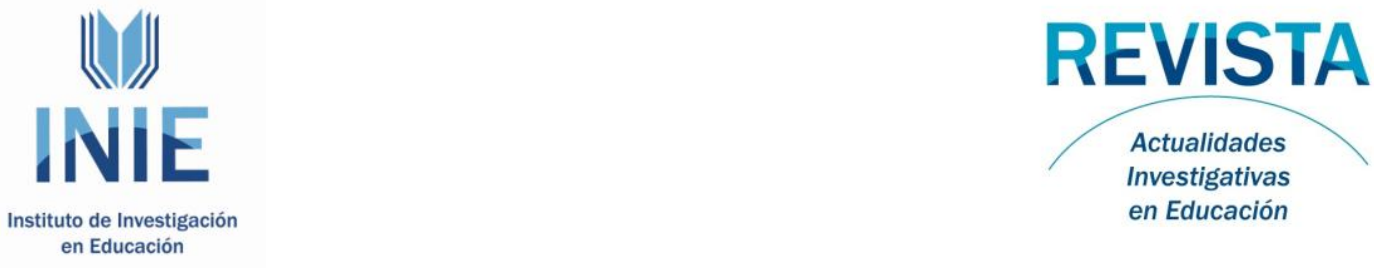

Actualidades Investigativas en Educación

Revista Electrónica publicada por el

Instituto de Investigación en Educación

Universidad de Costa Rica

ISSN 1409-4703

http://revista.inie.ucr.ac.cr

COSTA RICA

\title{
USO DE UN MEDIO TECNOLÓGICO EDUCATIVO EN EDUCACIÓN SUPERIOR COMO RECURSO DIDÁCTICO: REPORTE DE UNA EXPERIENCIA EN ODONTOLOGÍA
}

THE USE OF EDUCATIONAL TECHNOLOGY MEDIA IN HIGHER EDUCATION AS A TEACHING RESOURCE: DENTISTRY EXPERIENCE REPORT

Volumen 10, Número 2

pp. $1-21$

Este número se publicó el 30 de agosto de 2010

Orlando Maroto Marín

Marcela Quirós Garita

La revista está indexada en los directorios:

LATINDEX, REDALYC, IRESIE, CLASE, DIALNET, DOAJ, E-REVIST@S,

La revista está incluida en los sitios:

REDIE, RINACE, OEI, MAESTROTECA, PREAL, HUASCARAN, CLASCO 


\title{
USO DE UN MEDIO TECNOLÓGICO EDUCATIVO EN EDUCACIÓN SUPERIOR COMO RECURSO DIDÁCTICO: REPORTE DE UNA EXPERIENCIA EN ODONTOLOGÍA
}

\author{
THE USE OF EDUCATIONAL TECHNOLOGY MEDIA IN HIGHER EDUCATION AS A \\ TEACHING RESOURCE: DENTISTRY EXPERIENCE REPORT
}

\author{
Orlando Maroto Marín \\ Marcela Quirós Garita²
}

\begin{abstract}
Resumen: La elaboración de una herramienta tecnológica necesita una detallada investigación previa donde se determinan los problemas educativos que justifican su utilización; además, se analizan otros aspectos como los concernientes a las características de la población meta a la cual va dirigida; al respecto, las Tecnologías de la Información y de la Comunicación (TICs) han venido propiciando cambios en torno a la educación y a los sistemas de aprendizaje; sus alcances están siendo apreciados cada día más en los distintos centros de enseñanza a todo nivel. Por lo tanto, en este artículo se expone la experiencia de la elaboración y la validación de una herramienta tecnológica para el curso Restaurativa II en la Facultad de Odontología de la Universidad de Costa Rica (UCR); la utilización de la herramienta se propone como una ayuda para el aprendizaje del diseño de Prótesis Parcial removible que necesita de una buena preparación como base para obtener éxito en el tratamiento dental. Dicha experiencia fue bien acogida tanto por los estudiantes entrevistados como por los docentes.
\end{abstract}

Palabras clave: HERRAMIENTAS TECNOLÓGICAS Y ENSEÑANZA EN ODONTOLOGÍA, DISEÑO DE HERRAMIENTAS PARA LA ENSEÑANZA DE ODONTOLOGÍA, METODOLOGÍA DE LA ENSEÑANZA EN ODONTOLOGÍA.

\begin{abstract}
The development of a technological tool requires a detailed preliminary investigation to identify the educational problems that justify their use. Also it is necessary to explore other issues related to the characteristics of the target population to whom it is addressed, respect, Information and Communication Technologies have been encouraging changes around education and learning systems. His achievements are being increasingly appreciated in the different schools at all levels. Therefore this article describes the experience of the development and use of a multimedia tool for the "Restorative II" course at the Faculty of Dentistry of the University of Costa Rica, (UCR); the use of the tool is proposed as an aid for learning design removable partial denture that needs a good preparation as the basics for success in a dental treatment. This experience was well received both by interviewed students and professors.
\end{abstract}

Key words: TECHNOLOGICAL TOOLS AND EDUCATION IN DENTISTRY, TECHNOLOGY TOOL DESIGN FOR TEACHING ON DENTISTRY, TEACHING METHODOLOGIES ON DENTISTRY.

\footnotetext{
1 Licenciado en Odontología; Licenciado en Docencia en Odontología Máster en Tecnología Educativa Máster en Docencia y Currículo Universitario. Profesor interino Facultad de Odontología de la Universidad de Costa Rica. Dirección electrónica: orlandomaroto@gmail.com

2 Master en Tecnología Educativa con Énfasis diseño de medios. Diseñadora Industrial y Coordinadora del Centro de Diseño y Apoyo Audiovisual del Instituto de Investigaciones en Ingeniería, Facultad de Ingeniería, Docente de la Licenciatura de Diseño de Espacios Educativos y de la Escuela de Historia de la Universidad de Costa Rica. Dirección electrónica: marcelaq@inii.ucr.ac.cr
}

Artículo recibido: 14 de mayo, 2010

Aprobado: 9 de agosto, 2010 


\section{Introducción}

El proceso de enseñanza aprendizaje constituye todo un reto para cualquier docente, en todas las áreas y niveles. La utilización de medios que puedan atraer la atención y mejoren el aprendizaje puede convertirse en un aliado como recurso didáctico del docente. En la educación superior, la docencia exige no solo calidad, sino eficacia, para lograr que el alumno interiorice los conocimientos y sea capaz de llevarlos a la práctica, resolviendo los casos y los problemas que se le presenten, especialmente, en su ejercicio profesional.

En el campo de la Odontología, el estudiante debe desarrollar estas capacidades, de manera que pueda planear los tratamientos que brindará a los pacientes; por eso, es tan importante que el proceso pedagógico vivido en las aulas y laboratorios universitarios, le resulte significativo y suficiente para enfrentar las situaciones reales que tendrá que asumir, responsablemente, con su desempeño profesional.

A través de la tecnología educativa se puede tener la ayuda de una serie de recursos didácticos con los que se pueden relacionar los conocimientos teóricos y la resolución de casos de Odontología de forma simulada a través de medios digitales. Ningún programa sería capaz de desplazar la práctica clínica de los estudiantes de Odontología, pero sí podría ser de gran utilidad en los primeros cursos de carrera, donde la falta de experiencias suele constituir un problema en la concreción de los conocimientos teóricos con la práctica clínica.

Asimismo, al llegar a práctica clínica, los estudiantes tienen ya cerca de seis meses o un año de haber recibido sus clases teóricas sobre ciertos temas; cuando el estudiante ingresa a la clínica debe repasar sus apuntes y libros relacionados con el tema, de manera que empiece a realizar sus primeros tratamientos con la guía de su instructor.

Por tal motivo, en este artículo se expone la experiencia de la elaboración y del uso de una herramienta digital sobre prótesis parcial removible dentro de la enseñanza de Odontología, desde los análisis previos a su elaboración hasta la validación entre los estudiantes y docentes.

\section{Multimedios y Educación}

El término Multimedia presenta diferentes acepciones, unas referidas al software y otras al hardware, aunado a las definiciones de hipermedia e hipertexto que pueden confundir su contextualización. (Sarmiento, 2007). El mismo autor sugiere diferenciarlos de acuerdo con la sencuencialidad en la que se presenta la información, sea esta lineal o no 
lineal, lo que les distinguirá en materiales rígidos y menos rígidos. En estos últimos Sarmiento, M. agrupa los hipertextos, hipermedias y multimedias.

Aparici (1993), quien es citado por Póveda, L. y Rodríguez, M. (2010, p. 1) al referirse al multimedia dice que este: "...se denomina multimedia a la integración de diferentes medios audiovisuales. Pudiéndose distinguir dos tipos: los que pueden desarrollarse en soportes múltiples, integrando la información de manera complementaria (vídeo, audiocasete, libro, etc.) y los que lo hacen a través del ordenador". Y los hipertextos pueden definirse como: “... textos en los que se incluyen sistemas de acceso múltiple a la información" (García- Valcárcel, 2010, p. 1).

Para efectos de este trabajo se asumió como definición de multimedia: una herramienta en la que se integran varios medios a través de un software para utilizarla en un ordenador de forma integrada, es decir, esta herramienta se refiere al uso e integración de una serie de medios para transportar información, estos medios son: el texto, el video, las imágenes, los gráficos, las animaciones y la interactividad.

Con ella se utiliza más de un medio de comunicación simultáneamente como mencionan J. Cabero y Duarte (1999) citado por Sarmiento, M (2007, p. 2). El medio se considera como lo menciona Cabero, J. et al. (1999 p. 55), quien cita a Sureda y Salinas (1988, p. 159): “...como elemento vehiculador de mensajes...”, es decir, que lleva la información de forma escrita, oral u auditiva. La información se puede presentar con diferentes formatos, lo que podría atraer la atención del estudiante, además con la interactividad permitir al discente

Un multimedio puede ser un recurso didáctico, en cuyo caso, como menciona Cabero (2001), deberá ser encaminado hacia el cumplimiento de los objetivos y el alcance de los contenidos del curso, que están implícitos en el currículo vigente en la institución educativa; además, debe contemplar todas aquellas características propias de la población meta hacia la cual va dirigida.

El enfoque curricular que siga la universidad y, específicamente la facultad o escuela donde se implemente, es de vital importancia para el diseño de la herramienta tecnológica propuesta; sin embargo, se deben considerar dos aspectos en relación a este punto: lo primero que se debe recordar es que: “...el aprendizaje no se encuentra en función del medio..." (Cabero, 2001, p. 308), sino que se debe de acompañar de una serie de estrategias y de técnicas didácticas donde ocupe su función de medio para reforzar o alcanzar metas específicas, el medio debe de estar didáctica de estas (Aguilar, Morón, 
1994); y, lo segundo, el profesor podrá tener un papel de facilitador del aprendizaje, él se encargará de encauzar el uso de la herramienta, de manera que se obtenga el apoyo deseado, no debe de comportarse como un simple aplicador de recetas de acuerdo a la moda o a las tendencias (Aguilar, Morón, 1994).

La realidad será transformada a través del medio, y permitirá que el estudiante viva experiencias que le faciliten desarrollar habilidades cognitivas específicas, que incidirán en las destrezas psicomotoras que utilizará en su desempeño profesional.

Es importante que este medio tenga una alta capacidad de isomorfismo con la realidad, de esta manera, ayudará a preparar al profesional para que su paso hacia los procedimientos, que realizará en la clínica, sea más escalonado y su adaptación a las nuevas condiciones más rápida, lo que permitiría un mayor aprovechamiento de las experiencias con sus pacientes.

En este sentido, el uso de simuladores ha presentado, durante años, controversia en la educación; por ejemplo, los aviadores utilizan simuladores para aprender las destrezas de su profesión. Su elección podría relacionarse con aspectos como: la inversión y el riesgo necesarios para realizar las primeras prácticas en aviones de verdad.

En Odontología, podría ser poco ético practicar en seres humanos, además, los pacientes no suelen ser numerosos para la docencia como en otras épocas; asimismo, la opción de repetir tratamiento puede ser cara y engorrosa. Con una herramienta como la propuesta, los estudiantes podrían practicar y repasar antes de su práctica clínica.

Por tal motivo, se ha atribuido a esta herramienta la ventaja de ofrecer, simultáneamente, los canales mediante los cuales se comunican los seres humanos; es decir, gestos en el video, la comunicación auditiva a través de los sonidos, la visual a través de las imágenes y los textos.

Así las cosas, la herramienta educativa propuesta permite la interactividad con el usuario, que otros medios como la televisión no tienen (Aguilar, D, Morón, A 1994) aspecto que puede tornarse interesante para el estudiante, permitiéndole un aprendizaje activo.

\section{Fundamentación pedagógica de la herramienta multimedia}

En el caso de la herramienta propuesta, se fundamenta pedagógicamente en el constructivismo, ya que pretende que el estudiante aprenda haciendo, con las experiencias que desarrolle con su uso. 
El autor Díaz-Barriga (2002), en su libro: Estrategias para docentes para un aprendizaje significativo, una interpretación constructivista, cita a Mario Carretero, quien proporciona una definición del constructivismo

es la idea que mantiene que el individuo tanto en los aspectos cognitivos y sociales del comportamiento como los afectivos no es un mero producto del ambiente ni un simple resultado de sus disposiciones internas, sino una construcción propia que se va produciendo día a día como resultado de la interacción entre esos dos factores. En consecuencia, según la posición constructivista, el conocimiento no es una copia fiel de la realidad, sino una construcción del ser humano... (p. 27)

Con la herramienta se pretende que el estudiante pueda interactuar y desarrollar sus propios conocimientos con base a la experiencia que ya tenga y con la materia en clases.

De esta manera, el estudiante contará con una experiencia de aprendizaje que podrá desarrollar a su propio ritmo; este construirá sus nuevos conocimientos, a través de la interacción con la herramienta digital. A su vez, el apoyo del docente permitirá que el estudiante facilite su aprendizaje pero que este desarrolle sus propias ideas; además, con una concepción de que la tecnología es una herramienta con la que se media el aprendizaje, en esta ocasión el aprendizaje del diseño de las prótesis parciales removibles.

En este caso, como afirma Díaz- Barriga (2002), “...se sustenta en la idea de que la finalidad...es promover los procesos de crecimiento personal del alumno..." (p. 30), se alcanzará el conocimiento con análisis propios, el estudiante podría desarrollar su propio criterio profesional y que sea capaz posteriormente de resolver problemas dentro de su profesión. Se utilizará la zona de desarrollo actual, de manera que el discente aproveche sus conocimientos previos en el tema y los integre a los nuevos de manera que establezca una relación entre la zona de desarrollo próximo y la del desarrollo actual, lográndose un conocimiento propio.

\section{Fundamentación de la herramienta basada en la Teoría de la comunicación e información}

Parafraseando a Angel Batista (2010), en los procesos de enseñanza- aprendizaje presenciales, el docente dirige la acción formativa a través de múltiples y variadas estrategias y también medios didácticos; es así como menciona este autor que mediante este proceso de comunicación educativa, real, sincrónica y directa el docente media el Volumen 10, Número 2, Año 2010, ISSN 1409-4703 
acceso y la construcción de los conocimientos por parte de los estudiantes, y a través de la presencialidad el docente y los estudiantes tienen posibilidades reales de intercambio de información, para el trabajo independiente, cooperativo y colaborativo y, en todo este proceso, la intervención pedagógica del profesor está presente, potenciando, de esta manera, posibilidades de consultas, diálogos y participación de los estudiantes.

Continuando con el criterio de este autor, cuando el escenario o los entornos ya no son presenciales, frontales o de "cara a cara", sino que el proceso de enseñanza y aprendizaje se realiza en la casa del estudiante, mediante uso de herramientas de comunicación mediadas por el ordenador, debemos preguntarnos: ¿Cómo se realiza el proceso educativo con este nuevo modelo de enseñanza?, o preguntarnos también: ¿Cómo aprovechar el recurso tecnológico para mejorar el conocimiento y aún más los niveles comunicativos?

Al respecto, Batista considera que estas tecnologías, que han venido incorporándose en nuestros entornos educativos, deben ser reflexionadas, sistematizadas para que nos permitan adquirir las herramientas cognitivas e instrumentales necesarias para enseñar en estos nuevos entornos comunicativos virtuales, potenciados por la mediación del computador u ordenador y su debido uso, y así considerar estrategias didácticas apropiadas, que se incentiven y motiven el aprendizaje autónomo, independiente y a su vez cooperativo y colaborativo de los estudiantes. (Batista, 2010)

Con herramientas como la multimedia, se da la ruptura de las dimensiones espaciotemporales (Cabero, 2002), que traerá ventajas como: la individualización y la potenciación de la enseñanza flexible ya a distancia, o el acceso a fuentes de información no cercanas al estudiante, la información irá hasta el entorno doméstico del estudiante, en una programación controlada o determinada por el mismo, que va desde el tiempo que invierte con la herramienta, rutas o itinerarios que elige para construir su conocimiento, y grado de aprovechamiento. Por lo mencionado anteriormente, es indispensable tener claro que el grado de interactividad determina la calidad del producto (Cabero, 2002).

\section{Elaboración de la herramienta multimedia}

La elaboración de la herramienta multimedio, se estableció siguiendo el orden que se expone en la Figura 1: 


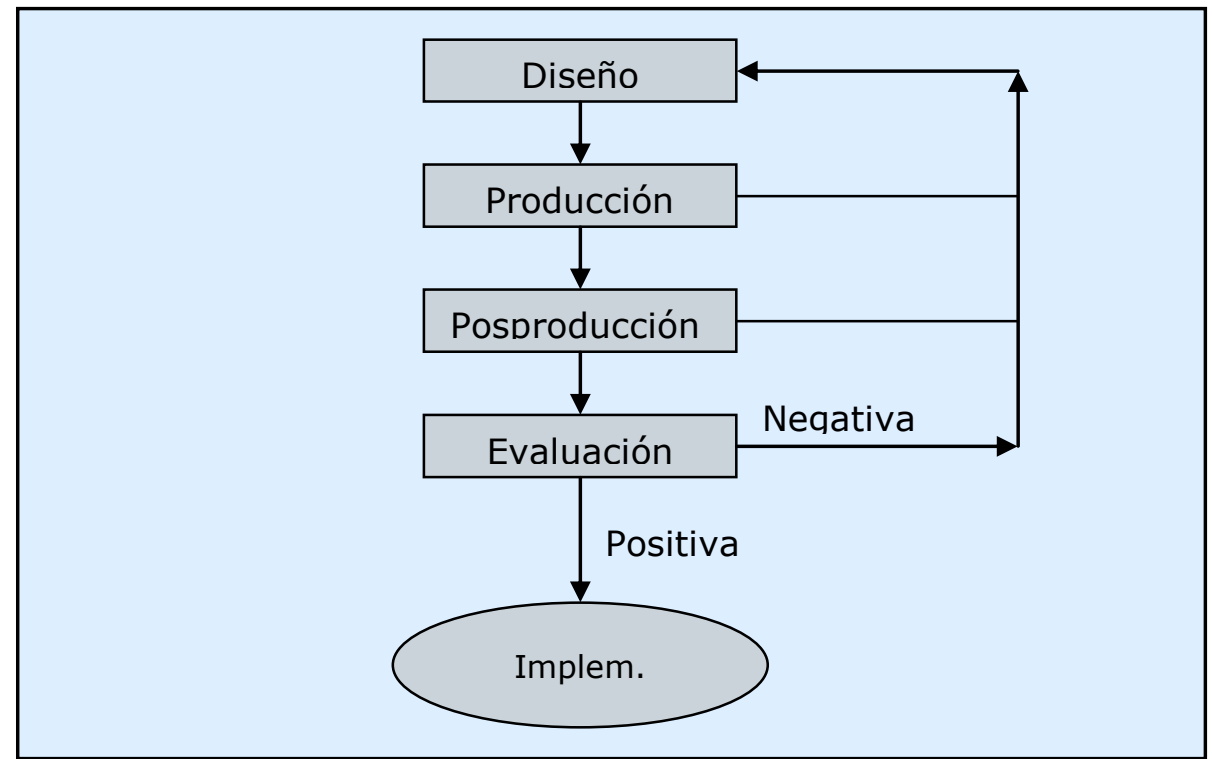

Figura 1. Secuencia de pasos para la elaboración de la herramienta multimedia. (Fuente: Maroto y Quirós, 2006)

Cada una de las etapas se llevó a cabo de manera tal que al final se evaluó el resultado obteniéndose la retroalimentación respectiva.

\section{Diseño}

El diseño se dividió en varias sub etapas a saber:
a. Análisis del contexto educativo para el que se diseñará la herramienta.
b. Descripción del usuario meta.
c. Necesidades del usuario meta.
d. Observación de otras herramientas de multimedia similares.
e. Selección del recurso humano y técnico.
f. Selección de contenidos pedagógicos.
g. Estructuración de la información. 


\section{a. Análisis de la situación}

Durante el análisis de la situación, se realizó una encuesta a los estudiantes que asistiría al curso Restaurativa Il al año siguiente al de la elaboración de la herramienta. Se tomaron datos como: número de estudiantes, lugar de residencia, edad promedio, colores preferidos, si tenían o no ordenador y el sistema operativo que utilizaban entre otras cosas.

Los criterios que se tomaron en cuenta estaban dirigidos a definir las características de la población meta que utilizaría después la herramienta digital. De acuerdo a esto, posteriormente se diseñaría seleccionando colores que le gustarían a la mayoría; además, el software con el cual se elaboraría y el diseño de las pantallas entre otras cosas.

\section{b. Descripción del usuario meta}

Se tomaron los datos obtenidos en las encuestas y se tipificó el usuario meta como: Jóvenes con edad promedio de 20 años, quienes residen en San José, se sienten satisfechos con la carrera que escogieron, no trabajan. Les agrada utilizar apoyo de imágenes para estudiar de manera que se pueda comprender mejor el contenido. En sus hogares utilizan el ordenador con frecuencia, equipos que cuentan con una configuración semejante a la siguiente: plataforma PC, con 128 Mb de memoria Ram, con 20 Gb de disco duro y además con acceso a Internet.

\section{c. Necesidades del usuario meta}

Para el análisis de la situación se realizó, también, un focus group con estudiantes que ya habían asistido al curso de Restaurativa II. Los objetivos perseguidos eran:

- Captar algunas de las percepciones y necesidades que tuvieron cuando llevaron el curso.

- Determinar, específicamente, qué contenidos o partes del curso presentan mayor dificultad de aprendizaje y por qué.

- Conocer cuáles son los temas de mayor interés para ellos.

- Determinar, a través de su experiencia, a qué puntos se les debe dar mayor énfasis, y/o requieren que el estudiante adquiera mayor destreza a través de medios virtuales. 
- Identificar los recursos que son percibidos por los estudiantes como de mayor riqueza, agrado o satisfacción para ilustrar los contenidos, de modo que las dificultades de aprendizaje puedan ser solventadas más eficazmente.

Con esta actividad se determinaron las debilidades del aprendizaje percibidas por los alumnos, resumiéndose sobre todo en la necesidad de observar casos reales que fueran expuestos desde el principio hasta el final.

d. Observación de otras herramientas de multimedia similares

Se revisaron herramientas semejantes para no repetir esfuerzos de aprendizaje en el mismo tema. Solamente se encontró un Cd, desarrollado en el año 2002, con contenidos teóricos relacionados con las prótesis totales y con las prótesis parciales. El formato de este era rígido en comparación con otras que poseen ejercicios interactivos, y a pesar de que los contenidos son muy ricos no se usa frecuentemente. Por último, se observaron también algunas herramientas de universidades extranjeras, donde se analizaron las características de navegación, profundidad de los contenidos, imágenes, etcétera.

\section{e. Selección del recurso humano y técnico}

Se determinaron las necesidades técnicas y de recursos humanos para la elaboración de la herramienta. Se tuvo la asistencia técnica del Instituto de Investigación para la educación (INIE) de la UCR (donde se suministró el servicio de un diseñador gráfico); asimismo, se tuvo el apoyo del departamento de Tecnología Educativa de la UNED y de la Facultad de Odontología de la UCR. Las fotografías, el diseño de las pantallas, el dibujo de muchos de los íconos fueron realizados por los autores del estudio.

\section{f. Selección de los contenidos pedagógicos}

Se buscó la colaboración del profesor encargado de coordinar el curso de Restaurativas II; por medio de este se coordinó una reunión con los docentes del laboratorio del curso, para que estos definieran los problemas principales con los que se enfrentan al desarrollarlo. Estos problemas fueron analizados en cuadros que se propusieron para cada uno, objetivos para solucionarlos y las acciones y medios digitales (vehiculización de la información) que podrían ayudar en su consecución. Se puntualizaron los contenidos de 
acuerdo con los objetivos de los problemas expuestos, tanto por los docentes, como por los estudiantes en el focus group.

Se utilizó un formato semejante al que se indica a continuación:

Cuadro № 1: Formato de análisis de problemas educativos detectados en la investigación previa a la elaboración de la herramienta.

\begin{tabular}{|l|l|l|l|l|l|}
\hline Problema & Objetivo & Contenido & $\begin{array}{l}\text { Estrategia } \\
\text { Pedagógica }\end{array}$ & Medios & $\begin{array}{l}\text { Indicadores } \\
\text { de logros }\end{array}$ \\
\hline 1. & & & & & \\
\hline
\end{tabular}

Con este cuadro de análisis se propusieron objetivos, contenido, estrategias metodológicas, medios para lograr solucionar los problemas y se determinaron indicadores de logros para cada uno de ellos. Estos últimos observables en los estudiantes.

\section{h. Estructuración de la información}

Los contenidos se escogieron de acuerdo con el análisis anterior. Se investigaron con libros de texto de la materia recomendados por el instructor del curso.

Con base en esto se organizaron y se estructuraron en un mapa conceptual, con el fin de obtener un orden lógico de desarrollo y de exposición de los temas de aprendizaje, según las etapas que comprende el diseño de prótesis parcial removible, para lo cual se contó con la colaboración del instructor del curso, quien realizó acotaciones importantes sobre el mapa conceptual para al final llegar a obtener una versión definitiva.

El mapa conceptual permitió facilitar la fase de guionización, por temas (módulos) y subtemas que abarca toda la temática de prótesis parcial removible; asimismo, definir el diseño tanto del menú principal y definir, a su vez, el mapa de navegación del usuario dentro de la herramienta para su mejor desempeño. Se debe aclarar que la navegación dentro de la herramienta se diseñó con cierto orden; sin embargo, el estudiante tendría plena libertad para escoger lo que necesitará o deseará revisar. 


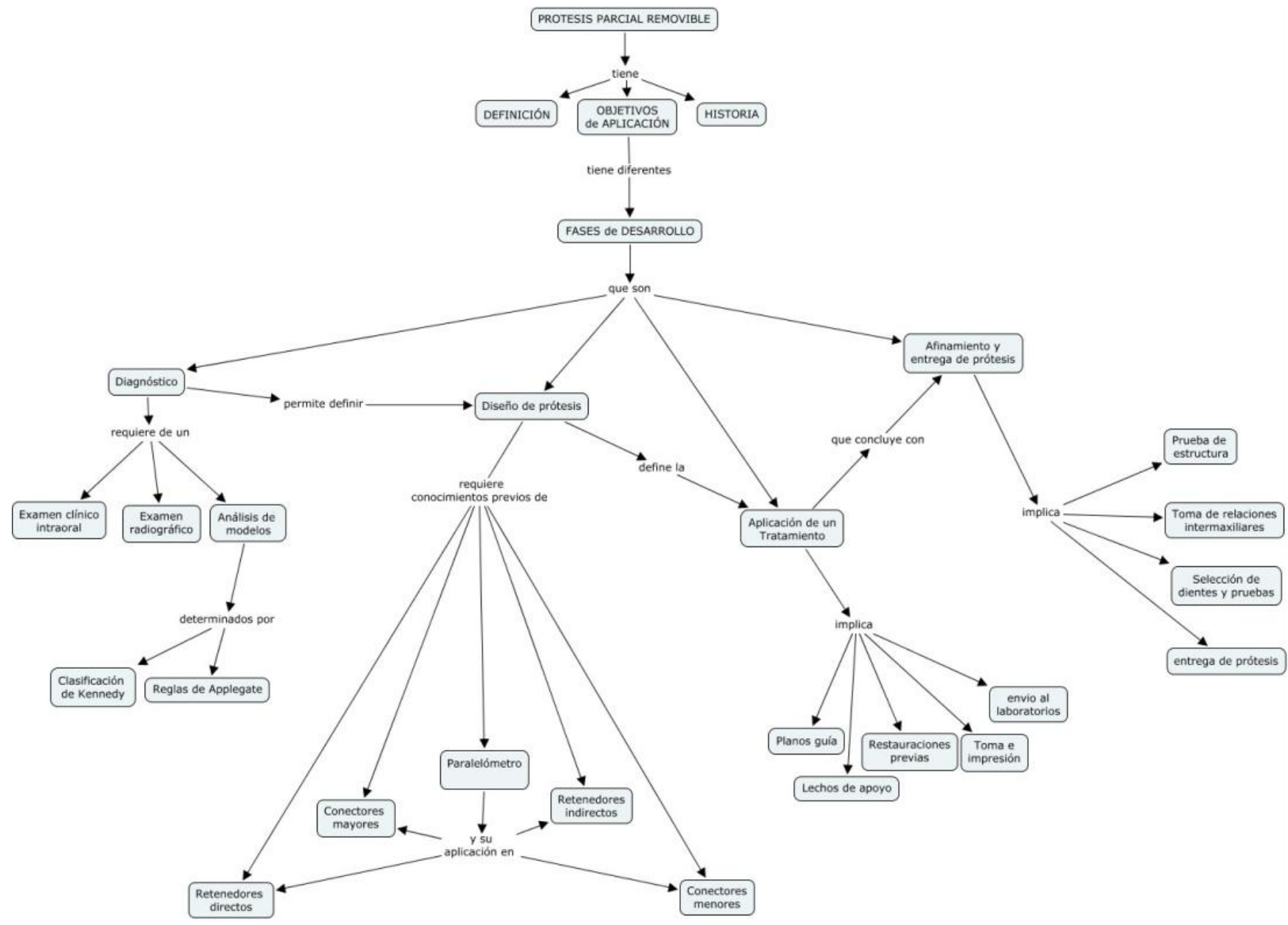

Figura 2. Mapa conceptual para el desarrollo del contenido del multimedio.

(Fuente: Maroto y Quirós, 2006) 


\section{INICIO}

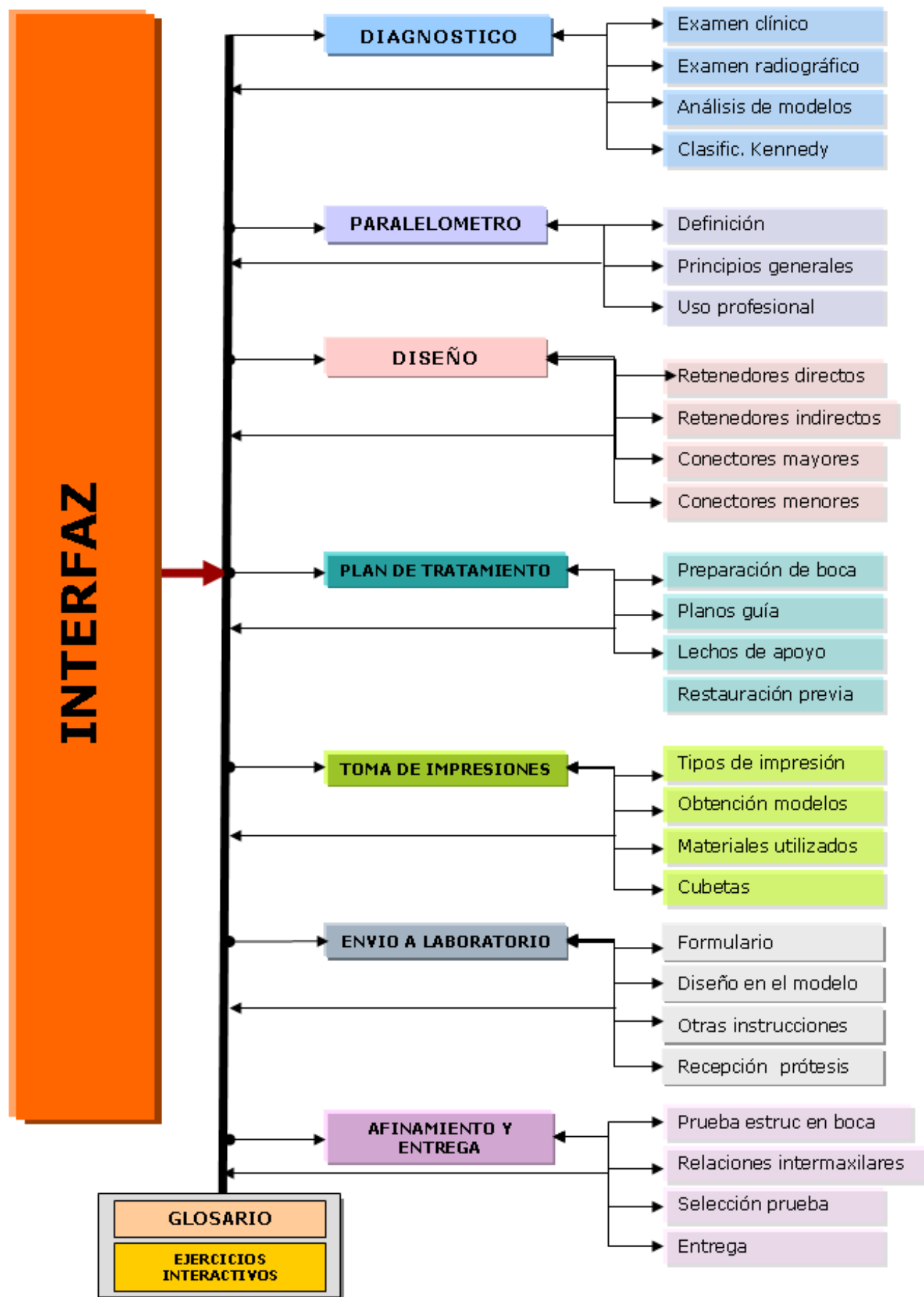

Figura 3. Mapa de navegación para el desarrollo del contenido del multimedio.

(Fuente: Maroto, O. y Quirós, M. 2006)

Volumen 10, Número 2, Año 2010, ISSN 1409-4703 


\section{Etapa de Producción}

En esta etapa se realizaron las siguientes acciones:
a. Diseño del guión literario.
b. Búsqueda de contenidos e imágenes.
c. Diseño del guión multimedio.
d. Diseño de la metáfora.
e. Interfaz gráfica.
f. Diseño del formato.
g. Diseño ergonómico de la interfaz.
h. Selección cromática para la aplicación.

A continuación, se detallan cada uno de los puntos citados anteriormente.

\section{a. Diseño del guión literario}

Primero, se elaboró un guión literario que incluye la descripción de la entrada de la herramienta y el acceso a los siete módulos de información; posteriormente se agregó un módulo de ejercicios interactivos y un glosario, este guión sirvió de base para ir concretando ideas en el diseño de la propuesta e ir aclarando el panorama de cómo trabajar cada módulo y los subtemas de desarrollo en cada uno de ellos, con el fin de no perder de vista el cumplimiento de rol pedagógico que debe de tener el multimedio. Además, durante la producción del prototipo, este orienta la labor del diseñador gráfico.

b. Búsqueda de contenidos e imágenes

Una vez realizado el planteamiento, se procedió, a la búsqueda de la información necesaria; en relación con los contenidos, se consultó el programa del curso y, además, se realizó una entrevista con el profesor coordinador del curso, quien recomendó el uso de textos específicos como base teórica.

Para desarrollar los contenidos se realizó la compilación de la información pertinente que permitiera cubrir los objetivos planteados con el multimedio.

Paralelamente a la búsqueda de contenidos, se buscaron imágenes de los libros recomendados que sirvieran para ilustrar la materia tratada en la herramienta. Asimismo, se realizó la captura de imágenes de casos de prótesis parcial removible, de la clínica de la Facultad de Odontología. 
c. Diseño del guión multimedio

Después de realizar la búsqueda de las imágenes y de los contenidos se procedió a realizar el guión multimedial formal, que se entregó al diseñador gráfico para que se iniciara la construcción de la herramienta. En este guión se plantearon los siguientes aspectos:

\section{Nombre del módulo}

Imagen: La imagen relacionada con el módulo.

Sonido: Descripción del sonido, características

de la locución...on/off.

Texto: Submenú, títulos y contenidos.

Acción: Las acciones que tienen los botones en

el submenú u otros como los de regreso o avance.

Figura 4. Estructura del guión multimedial.

(Fuente: Maroto y Quirós, 2006)

\section{d. Diseño de la metáfora}

En el caso de esta herramienta, se trató de recrear las características del laboratorio donde el estudiante recibe las clases de prótesis parcial removible.

Para el diseño de la metáfora multimedio se debe recordar que el objeto es dar una descripción de una situación desconocida a partir de una conocida, de manera que se acelere su comprensión y su aprendizaje.

Entonces, se consideró recrear, por medio de la herramienta, el ambiente cotidiano que vivirá el estudiante durante el transcurso del curso de Restaurativas II. El objetivo es que cuando el estudiante ingrese a la herramienta, se logre disponerlo y ubicarlo mentalmente en el ambiente de trabajo que va a tener o que ya tiene. De acuerdo con lo anterior, se planeó iniciar con un saludo de bienvenida; además, con una animación con algunos de los elementos principales que componen una prótesis parcial removible, y con el recorrido que sigue un estudiante desde la calle hasta el laboratorio donde el estudiante recibe las lecciones, terminando en la mesa de trabajo respectiva. Todas las acciones anteriores se presentan utilizando, además, música de fondo que las motiva. 


\section{e. Interfaz gráfica}

Una interfaz gráfica se relaciona con el medio a través del cual el usuario localiza a través del menú aquellos elementos a través que desea acesar a través del clic del ratón.

Párrafo 1. Se consideró necesario durante la producción de la herramienta el diseño de una interfaz gráfica, capaz de ubicar de manera clara y sencilla al estudiante con los contenidos que en ella se desarrollan; esto se logra a través del escenario de la mesa de trabajo, en donde cada uno de elementos que allí se disponen tienen la funcionalidad de botones, a través de los cuales se ofrece el menú principal con el que se puede iniciar el desplazamiento o la navegación a los diferentes módulos de su contenido.

Luego de que el usuario realiza su selección e ingresa a cualquiera de los módulos del multimedia, se presenta en la pantalla principal de cada módulo un submenú que le llevará, específicamente, al tema de su elección.

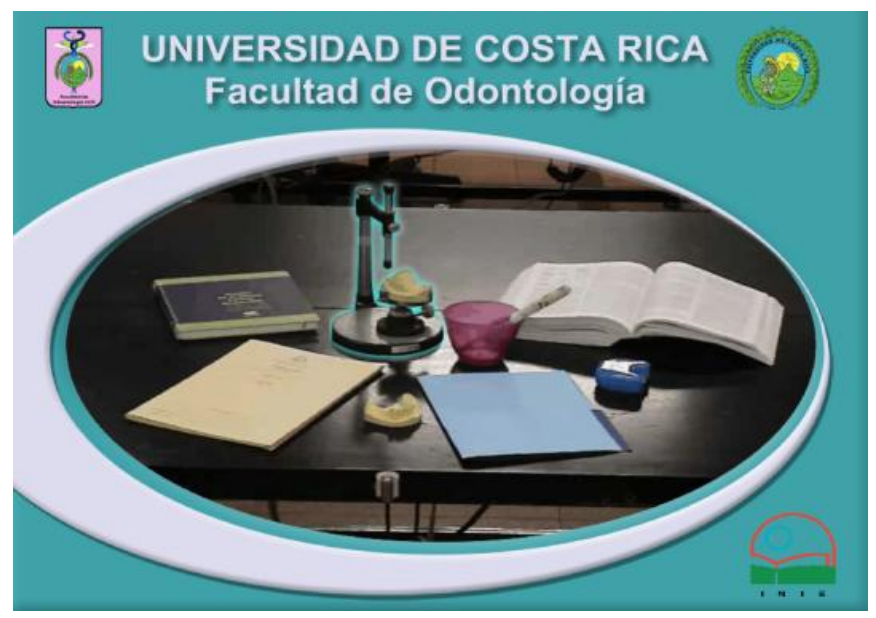

Figura 5. Diseño de pantalla del menú principal del multimedia

(Fuente: Maroto y Quirós, 2006)

\section{f. Diseño del formato}

En cuanto al diseño planteado para las pantallas de cada módulo, se realizó un estudio de proporcionalidad, con el fin de definir áreas de trabajo eficaces para colocar la información correspondiente al: menú principal, submenú, la identificación de la pantalla para ubicar al usuario, contenidos, entre otros.

Para obtener esta proporcionalidad, se partió de las dimensiones de pantalla de $800 \mathrm{x}$ 600 píxeles, que es un tamaño estándar de resolución, con el que se obtiene una mayor 
certeza de cubrir el mayor porcentaje de disponibilidad tecnológica de la población en cuestión. A esta dimensión, se le aplicó la sección áurea.

Esta ley universal, cuyo principio estético es aplicado en arquitectura, escultura y pintura, así como en todos los campos del arte, se le atribuye su descubrimiento al arquitecto romano Marco Vitruvio, en el siglo I d.c., y su razonamiento es el siguiente:

- El segmento menor mantiene con respecto al mayor la misma proporción armónica que este con respecto a la totalidad.

A. C. B

El punto $C$ crea una sección áurea en el segmento rectilíneo $A B$ sí $A C / A B=C B / A C$.

- Un espacio dividido en partes desiguales resulta más agradable y estético, si entre la parte pequeña y la mayor existe la misma relación que entre cada una de ellas y el todo.
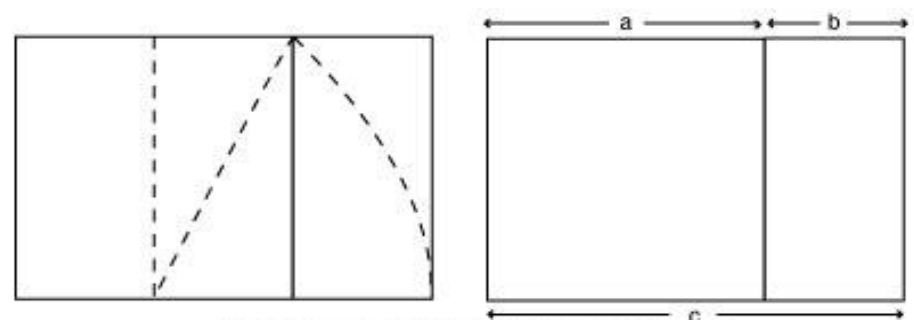

Figura 6. Sección áurea y rectángulo áureo

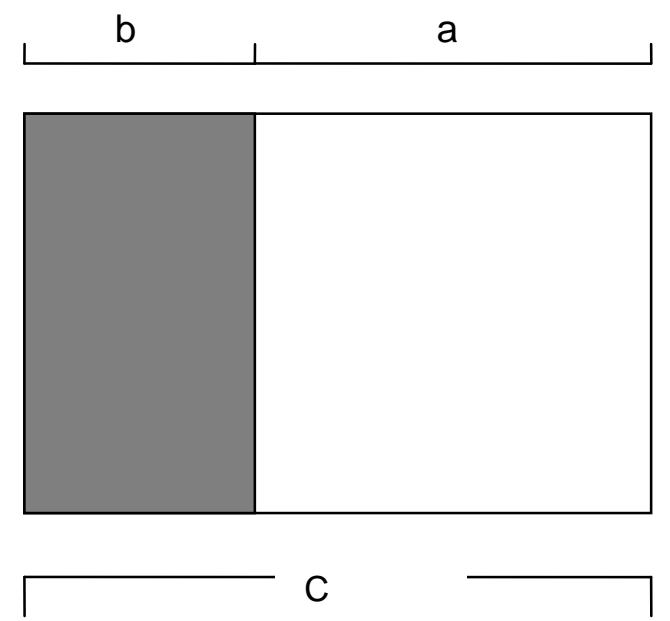

Figura 7. Justificación de la división gráfica del espacio las pantallas. 

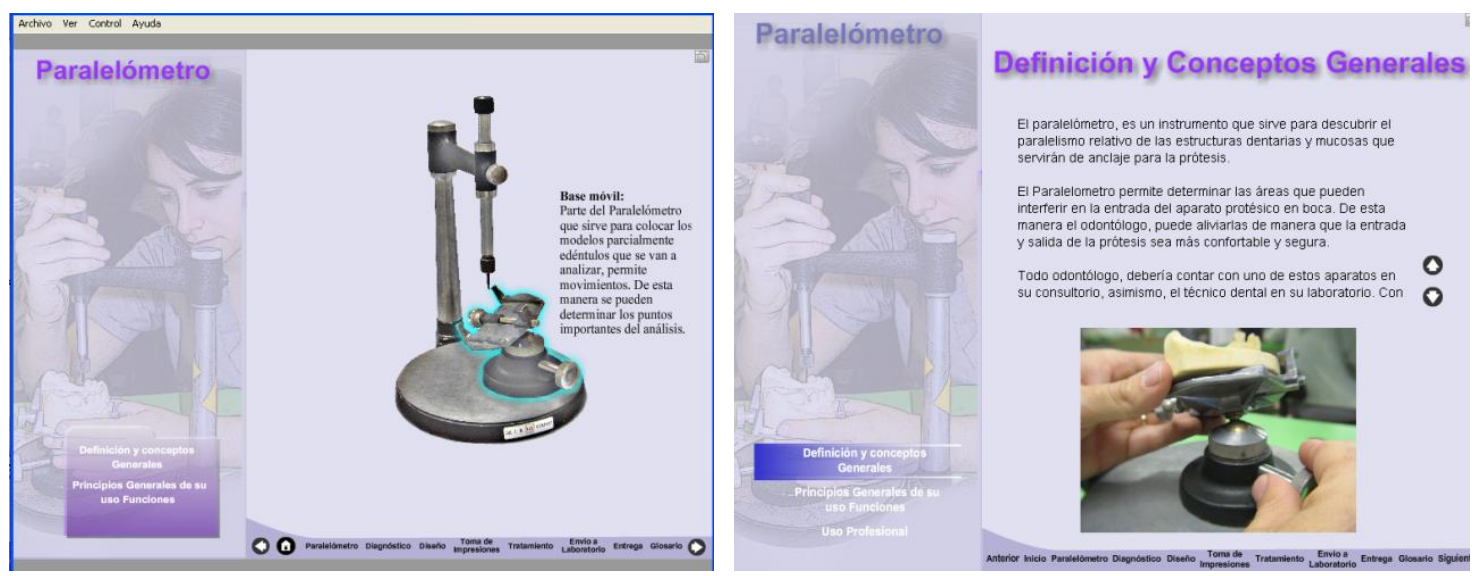

Figura 8. Ejemplo de algunas pantallas diseñadas, en el área izquierda de la pantalla se ubica el submenú de cada módulo. En parte inferior de cada pantalla, se ubicó el menú principal para mejorar la usabilidad de la herramienta y está representado por un ícono similar a los botones de la pantalla de entrada principal.

\section{h. Diseño ergonómico de la interfaz}

Según lo explicado en el punto anterior, el área de color más claro y de mayor espacio será utilizada para incluir actividades interactivas que se han planificado y, a su vez, esta misma área está dispuesta para el desarrollo de los contenidos e imágenes que los ilustran.

En la parte inferior del área clara se ubicará el menú principal, que acompañará al usuario durante toda su navegación de una manera discreta y estética; además, se colocan íconos semejantes a los elementos que se representan en el menú principal de entrada.

En la pantalla el color más intenso se utiliza para ubicar una imagen que identifique el módulo seleccionado por el usuario. En la parte inferior de esta sección se colocó un submenú con el que el usuario podrá escoger los temas de su interés. Para representar el submenú, se utilizó hipertexto, es decir, hipervínculos que hacen aparecer los datos en el área clara, con el fin de otorgar simplicidad, pureza, flexibilidad y de no recargar con muchas imágenes las pantallas.

La tipografía Arial fue seleccionada para el texto, ya que entre sus características principales tiene la legibilidad, cualidad que es propia de las tipografías de las familias de Palo Seco a la que pertenece, por ser compacta, con lo que se garantiza la economía del espacio sin sacrificar funcionalidad. Además, está presente en la mayoría de ordenadores con lo que, también, se logra mayor compatibilidad con visualización. 


\section{i. Selección cromática para la aplicación}

Uno de los aspectos relevantes en el diseño del multimedia está constituído por el uso y la aplicación de los colores, la elección va más allá de la estética. El color es un elemento de diseño que tiene su protagonismo en el aspecto visual de la herramienta, ya que será utilizado, específicamente, con el fin de proporcionarle al usuario una presentación más atractiva y agradable. El color se convierte en un código que le permitirá identificar, fácilmente, los diferentes módulos, ya que cada uno tendrá una combinación diferente, y además tendrá coincidencia con el color de los botones del menú principal

El criterio que se tomó para seleccionar los colores se relacionó con los diferentes colores de los uniformes que utilizan los estudiantes en la Facultad de Odontología que son: celeste, turquesa, gris y verde, para que el estudiante se sienta familiarizado con la herramienta.

\section{Resultados de la implementación}

La herramienta fue probada con un grupo de 10 estudiantes que habían cursado recientemente Restaurativas II, con el propósito de identificar el valor percibido por los estudiantes dentro de su propio proceso de enseñanza aprendizaje y, además, de identificar la utilidad dentro del curso clínico.

A cada uno de los estudiantes se les entregó una versión terminada de la herramienta que podían revisar durante 22 días; posteriormente, les pasó una encuesta para verificar sus impresiones sobre el uso de la herramienta. Se tomaron en cuenta aspectos como: la utilidad de la herramienta dentro del proceso de aprendizaje de las prótesis parciales, calidad de las imágenes, facilidad de su uso, utilización del menú, pertinencia de los textos, calidad de los colores y del diseño.

En su mayoría, los estudiantes calificaron la herramienta como excelente en cuanto a pertinencia y a calidad dentro del aprendizaje de la materia de prótesis; además, consideraron que en los otros aspectos de diseño y de uso del menú fueron considerados de excelentes a buenos. El único aspecto en el que se recomendó revisión fue el de los ejercicios interactivos, en los que se recomendó revisión de conceptos.

También, se realizó un focus group con algunos profesores involucrados con la materia Restaurativa II, quienes determinaron que la herramienta era útil dentro de la docencia de la materia, aunque algunos textos debían revisarse y ampliarse. Expresaron su aprobación en relación con el uso de la herramienta siempre y cuando se realizaran los cambios Volumen 10, Número 2, Año 2010, ISSN 1409-4703 
pertinentes en relación a algunos textos. La dinámica del uso de la herramienta fue considerada como bueno en general; los colores y el uso de las imágenes fueron calificados como muy bueno. Finalmente, se recomienda colocar la herramienta en línea, para mayor accesibilidad por parte de los estudiantes.

\section{Resumen}

Se elaboró una herramienta educativa digital para ser utilizada dentro del proceso enseñanza aprendizaje en el curso Restaurativas // de la carrera de Odontología de la Universidad de Costa Rica.

La confección de la herramienta necesitó de una serie de procesos como el estudio de la situación previa, para así determinar los problemas educativos por resolver; además, la elaboración de varios guiones como: el didáctico y el multimedio. Se realizó un estudio previo de la población que utilizaría la herramienta, para lo que se llevaron a cabo una serie de estudios sobre las preferencias de colores entre otras cosas y sobre su accesibilidad a este tipo de herramientas.

Todos los estudios se realizaron dentro del marco curricular vigente en la Facultad y respetando en todo momento el criterio de los docentes del curso.

\section{Conclusiones}

- La elaboración de una herramienta de multimedio necesita todo un estudio previo, desde la problemática educativa a la que responde hasta la caracterización de la población meta.

- Es necesario trabajar, en todo momento, acorde con los lineamientos curriculares de la Facultad o de la institución educativa en la que se vaya a implementar la herramienta.

- La recolección de imágenes, así como la investigación de los conceptos tratados necesitan que el investigador tenga cierto conocimiento sobre el tema y la total colaboración del docente o de los docentes involucrados. 
- La herramienta fue evaluada tanto por los estudiantes como por los docentes, como un recurso de utilidad para mejorar el aprendizaje del curso de Restaurativas II, el área de prótesis parcial.

- Es importante que esta herramienta reciba actualizaciones pertinentes de acuerdo a las necesidades o avances del tema.

\section{Referencias}

Aguilar, Diego; Morón, Alfonso. (1994). Multimedia en Educación. Recuperado el 3 de marzo del 2010, de http://dialnet.unirioja.es/servlet/articulo?codigo=635418

Batista, Santiago. (2002). Compromisos de la evaluación educativa, España: Prentice Hall.

Batista, Ángel. (2010). La comunicación educativa en los nuevos entornos de formación: el rol del docente y la utilización de herramientas didácticas y herramientas. Recuperado el 15 de junio del 2010, de telemáticas www.tecnologiaedu.us.es/simposio-iberoamericano/ponencias/pdf/PA.1.45.pdf

Brophy, Jere et al. (1996). Psicología de la Educación Contemporánea (5ta ed.). México: Editorial Mc Graw Hill.

Cabero, Julio. (2001). Tecnología Educativa. Diseño y utilización de medios en la enseñanza. Barcelona España: Editorial Paidós Ibérica S.A.

Cabero, Julio et al. (1999). Tecnología Educativa. España: Editorial Síntesis.

Clares, José. (2005). Guía Teórico Práctica para la elaboración de Programa Educativo Multimedia. Madrid, España: UNED.

Davenport, John et al. (1992). Atlas en color de prótesis parcial removible. Londres, Inglaterra: Editorial Mosby- Wolfe.

Díaz Barriga, Frida. (1998 y 2002). Estrategias Docentes para un aprendizaje significativo (1a y $2 a$ ed.) México: Mc Graw Hill.

García, José Luis et al. (2005). Diseño de Prótesis Parcial Removible. Secuencia práctica y lógica para su diseño. Venezuela: Editorial Amolca.

García, Ana. Prácticas Fundamentales de Tecnología Educativa. Recuperado el 20 de junio 2010, de www.dialnet.unirioja.es/servlet/extaut?codigo $=185963$

Gómez, Sandra. (2003). El profesor ante las nuevas tecnologías de información y comunicación. NITC. Revista Digital de Educación y Nuevas Tecnologías, 
Contexto Educativo, 28 nota 05. Recuperada el 26 de junio del 2006. http://contextoeducativo.com.ar/2003/4/nota-05.htm

Hernández, Roberto et al. (2003). Metodología de la Investigación (3 ${ }^{a}$ ed.). México: Editorial Mc Graw Hill Interamericana.

Maroto, Orlando; Quirós, Marcela. (2006), Diseño de una herramienta multimedia educativa para facilitar el proceso de aprendizaje en el curso de restaurativa II de la facultad de Odontología de la Universidad de Costa Rica. Tesis de grado, para optar por el Título de Máster en Tecnología Educativa con énfasis en producción de medios instruccionales. San José, Costa Rica, UNED.

Mc Givney, Glen et al. (2004). Mc Craken Prótesis Parcial Removible. Buenos Aires, Argentina: Editorial Panamericana.

Mainieri, Aida; Méndez, Zaira. (1985). Detección de problemas de aprendizaje San José, Costa Rica: EUNED.

Méndez, Zaira. (1991). Aprendizaje y Cognición, San José, Costa Rica, EUNED.

Lechner, Sybille. (2009). Evaluation of teaching and learning strategies. Recuperado en abril de 2010 de http://med-ed-online.net/index.php/meo/article/view/4529

Ruiz, Roger. (2006). Estudio sobre el estilo comunicativo empleado por médicos residentes y los elementos que influyen para mejorarlo. Recuperado el 17 de junio del 2006 de www.siicsalud.com/dato/dat046/05n17010.htm

Sarmiento, Mariela. (2007). La enseñanza de las matemáticas y las Ntic. Una estrategia de formación permanente (Capítulo 42). Recuperada el 11 de junio del 2010 en www.tesisenxarxa.net/TDX-0806107-121312/ 